\title{
Comparisons of selection indices achieving predetermined proportional gains
}

\author{
Y. ITOH and Y. YAMADA \\ Department of Animal Science, College of Agriculture, Kyoto University, Kyoto 606, Japan
}

\begin{abstract}
Summary
There are 3 different selection indices to achieve predetermined proportional gains in some traits. One is a modification of the restricted selection index of KEMPTHORNE \& NoRDSKOG (1959) and the others are indices with proportional constraints proposed by HARviLLE (1975) and TALLIS (1985). They are described in uniform notations and their equivalence is proved algebraically.
\end{abstract} tion.

Key words: Restricted selection index, proportional constraints, improvement in desired direc-

\author{
Résumé \\ Comparaison d'indices de sélection pour des gains \\ respectant des proportions fixées à l'avance
}

Il existe 3 indices de sélection différents qui permettent d'obtenir des gains respectant des proportions fixées à l'avance. L'un résulte d'une modification de l'indice de sélection restreint de KEMPTHORNE \& NORDSKOG (1959) ; les 2 autres sont des indices avec contraintes proportionnelles proposés par HaRville (1975) et Tallis (1985). Ils sont décrits avec des notations homogènes et leur équivalence est démontrée algébriquement.

Mots clés : Index de sélection restreint, contraintes proportionnelles, progrès dans une direction.

\section{Introduction}

KEMPTHORNE \& NORDSKOG (1959) proposed a selection index which ensured zero selection gain in some character. TALLIS (1962) extended their method and proposed an index which allowed progresses to pre set optimal levels in certain characters. However, MALLARD (1972) criticized that the method of TALlis was not optimal and indicated how optimality could be achieved.

HARVILLE (1975) proposed an index with proportional constraints which shifted the 
means of some characters in desired direction. This method was more efficient than the procedure of TALLIS. Recently TALLIS (1985) accepted the criticism and presented a more general solution to this original effort. On the other hand, Mallard (1972) suggested that proportional constraints could be converted into zero progress restrictions of some linear combinations of characters and the index of KEMPTHORNE \& NoRDSKOG was also applicable for the purpose (condition 2 in his paper).

Therefore there are 3 different selection indices to achieve the same purpose, i.e. the indices of Kempthorne \& Nordskog (1959), Harville (1975) and Tallis (1985), but they look quite different from each other. We have tried to make it clear what relationships exist among them and which are the best. Finally we found that all of them are equivalent.

The objectives of this paper are to describe these indices in an uniform notation and to prove their equivalence.

\section{Notation}

We use the following notations.

$t=$ the number of characters taken into the index.

$r=$ the number of characters on which proportional constraints of gains are imposed.

$\mathbf{g}_{1}=r \times 1$ vector of additive genotypic values of characters on which proportional constraints are imposed.

$\mathbf{g}_{2}=(t-r) \times 1$ vector of additive genotypic values of characters on which proportional constraints are not imposed.

$\mathbf{g}=\left[\begin{array}{l}\mathbf{g}_{1} \\ \mathbf{g}_{2}\end{array}\right]$

$\mathbf{a}_{1}=r \times 1$ vector of relative economic weights corresponding to $\mathbf{g}_{1}$.

$\mathbf{a}_{2}=(t-r) \times 1$ vector of relative economic weights corresponding to $\mathbf{g}_{2}$.

$\mathbf{a}=\left[\begin{array}{l}\mathbf{a}_{1} \\ \mathbf{a}_{2}\end{array}\right]$

$H=\mathbf{a}^{\prime} \mathbf{g}$, aggregate genotypic value.

p $=t \times 1$ vector of phenotypic values.

b $=t \times 1$ vector of index weights.

$I=\mathbf{b}^{\prime} \mathbf{p}$, selection index. 
$\mathbf{G}=\operatorname{Cov}(\mathbf{p}, \mathbf{g}), t \times t$ covariance matrix between phenotypic values and additive genotypic values.

$\mathbf{G}_{1}=\operatorname{Cov}\left(\mathbf{p}, \mathbf{g}_{1}\right)$.

$\mathbf{G}_{2}=\operatorname{Cov}\left(\mathbf{p}, \mathbf{g}_{2}\right)$.

$\mathbf{P}=\operatorname{Var}(\mathbf{p}), t \times t$ phenotypic variance covariance matrix.

$\mathbf{k}=r \times 1$ vector of predetermined proportional gains in $r$ characters.

1II. The index of Tallis (1985)

First we describe the constrained selection index derived by Tallis (1985). Expected genetic progresses of $g_{1}$ after selection using the index $I=\mathbf{b}^{\prime} \mathbf{p}$ can be written as :

$$
\mathrm{E}\left(\Delta \mathbf{g}_{1}\right)=i \mathbf{G}_{1}^{\prime} \mathbf{b} / \sigma_{l}
$$

where $i$ is the intensity of selection and $\sigma_{t}$ is the standard deviation of the index, i.e. $\sigma_{l}=\sqrt{\mathbf{b}^{\prime} \mathbf{P b}}$. Therefore proportional constraints of progresses can be expressed as :

$$
\mathbf{G}_{1}^{\prime} \mathbf{b}=\theta \mathbf{k}
$$

where $\theta$ is a scalar which is indeterminate a priori. Minimizing $\operatorname{Var}(I-H)$ subject to the constraints $\mathbf{G}_{1}^{\prime} \mathbf{b}=\theta \mathbf{k}$, we get the equations :

$$
\left[\begin{array}{cc}
\mathbf{P} & \mathbf{G}_{1} \\
\mathbf{G}_{1}^{\prime} & \mathbf{O}
\end{array}\right]\left[\begin{array}{l}
\mathbf{b} \\
\boldsymbol{\gamma}
\end{array}\right]=\left[\begin{array}{c}
\mathbf{G a} \\
\theta \mathbf{k}
\end{array}\right]
$$

where $\boldsymbol{\gamma}$ is a vector of Lagrange multipliers. Solving these equations as to $\mathbf{b}$, we get :

$$
\begin{aligned}
\mathbf{b}_{\mathrm{T}} & =\left[\mathbf{I}-\mathbf{P}^{-1} \mathbf{G}_{1}\left(\mathbf{G}_{1}^{\prime} \mathbf{P}^{-1} \mathbf{G}_{1}\right)^{-1} \mathbf{G}_{1}^{\prime}\right] \mathbf{P}^{-1} \mathbf{G a}+\theta \mathbf{P}^{-1} \mathbf{G}_{1}\left(\mathbf{G}_{1}^{\prime} \mathbf{P}^{-1} \mathbf{G}_{1}\right)^{-1} \mathbf{k} \\
& =\left[\mathbf{I}-\mathbf{P}^{-1} \mathbf{G}_{1}\left(\mathbf{G}_{1}^{\prime} \mathbf{P}^{-1} \mathbf{G}_{1}\right)^{-1} \mathbf{G}_{1}^{\prime}\right] \mathbf{P}^{-1} \mathbf{G}_{2} \mathbf{a}_{2}+\theta \mathbf{P}^{-1} \mathbf{G}_{1}\left(\mathbf{G}_{1}^{\prime} \mathbf{P}^{-1} \mathbf{G}_{1}\right)^{-1} \mathbf{k}
\end{aligned}
$$

We must choose $\theta$ which minimizes $\operatorname{Var}\left(\mathbf{b}_{\mathrm{T}}^{\prime} \mathbf{p}-H\right)$, and we can get such $\theta$ by putting the derivative of $\operatorname{Var}\left(\mathbf{b}_{\mathrm{\gamma}}^{\prime} \mathbf{p}-H\right)$ as to $\theta$ to zeros. Then we get :

$$
\boldsymbol{\theta}^{*}=\mathbf{a}^{\prime} \mathbf{G}^{\prime} \mathbf{P}^{-1} \mathbf{G}_{1}\left(\mathbf{G}_{1}^{\prime} \mathbf{P}^{-1} \mathbf{G}_{1}\right)^{-1} \mathbf{k} / \mathbf{k}^{\prime}\left(\mathbf{G}_{1}^{\prime} \mathbf{P}^{-1} \mathbf{G}_{1}\right)^{-1} \mathbf{k}
$$

This is the result derived by TALLIS (1985).

The vector $b_{\mathrm{T}}$ of (3) can be partitioned into 2 parts as :

$$
\mathbf{b}_{\mathrm{T}}=\mathbf{b}_{1}+\boldsymbol{\theta}^{*} \mathbf{b}_{2}
$$

where :

$$
\begin{aligned}
& \mathbf{b}_{1}=\left[\mathbf{I}-\mathbf{P}^{-1} \mathbf{G}_{1}\left(\mathbf{G}_{1}^{\prime} \mathbf{P}^{-1} \mathbf{G}_{1}\right)^{-1} \mathbf{G}_{1}^{\prime}\right] \mathbf{P}^{-1} \mathbf{G}_{2} \mathbf{a}_{2} \\
& \mathbf{b}_{2}=\mathbf{P}^{-1} \mathbf{G}_{1}\left(\mathbf{G}_{1}^{\prime} \mathbf{P}^{-1} \mathbf{G}_{1}\right)^{-1} \mathbf{k}
\end{aligned}
$$


The vector $\mathbf{b}_{1}$ represents the weights of the restricted selection index of KEMPTHORNE \& NoRDSKOG (1959) with the restriction that expected genetic progresses of $\mathbf{g}_{1}$ are equal to zeros, i.e. $\mathrm{E}\left(\Delta \mathbf{g}_{1}\right)=\mathbf{0}$. The vector $\mathbf{b}_{2}$ represents the weights of the index leading to the greatest improvement in desired direction independently of economic weights, which was derived by Harville (1975), Yamada et al. (1975), Rouvier (1977), Essl (1981) and Tallis (1985). Hence the index weights $\mathbf{b}_{\mathrm{T}}$ are linear combinations of the index weights achieving zero and maximum progresses of $\mathbf{g}_{1} \cdot \theta^{*}$ represents the regression coefficient of $H$ on $I_{2}$ because the numerator and the denominator of (4) represent :

$$
\begin{aligned}
& \mathbf{a}^{\prime} \mathbf{G}^{\prime} \mathbf{P}^{-1} \mathbf{G}_{1}\left(\mathbf{G}_{1}^{\prime} \mathbf{P}^{-1} \mathbf{G}_{1}\right)^{-1} \mathbf{k}=\operatorname{Cov}\left(H, I_{2}\right) \text { and } \\
& \mathbf{k}^{\prime}\left(\mathbf{G}_{1}^{\prime} \mathbf{P}^{-1} \mathbf{G}_{1}\right)^{-1} \mathbf{k}=\operatorname{Var}\left(I_{2}\right),
\end{aligned}
$$

respectively.

This index is not always appropriate and it depends on the sign of $\theta^{*}$, which is equal to the sign of $\operatorname{Cov}\left(H, I_{2}\right)=\mathbf{a}^{\prime} \mathbf{G}^{\prime} \mathbf{P}^{-1} \mathbf{G}_{1}\left(\mathbf{G}_{1}^{\prime} \mathbf{P}^{-1} \mathbf{G}_{1}\right)^{-1} \mathbf{k}$. If $\boldsymbol{\theta}^{*}>0$, it is appropriate, and there is no problem. However, if $\theta^{*}<0$, the index will move the population means in the opposite direction to the predetermined desired direction, and if $\theta^{*}=0$, it results in no selection gain in $\mathbf{g}_{1}$. These cases are caused by contradiction between the economic weights and the predetermined desired direction of improvement, and in such cases this index has no meaning in practice.

\section{The index of HARviLle (1975)}

The index of Tallis (1985) is equivalent to that of Harville (1975), as pointed out by TAllis (1985). HaRville derived his result by maximizing the correlation coefficient between the true aggregate genotypic value and the index, $\rho\left(\mathbf{b}^{\prime} \mathbf{p}, H\right)$, subject to the constraints $\mathbf{G}_{1}^{\prime} \mathbf{b}=\theta \mathbf{k}$ and that the variance of the index equals to unity, i.e. $\mathbf{b}^{\prime} \mathbf{P b}=1$.

Put $B=\left\{\mathbf{b} \mid \mathbf{G}_{1}^{\prime} \mathbf{b}=\theta \mathbf{k}, \theta\right.$ arbitraty $\}$, then according to TAllis (1985), the vector $\mathbf{b}$ which satisfies :

$$
\min _{\boldsymbol{\theta}} \min _{\mathbf{b} \in B} \operatorname{Var}\left(\mathbf{b}^{\prime} \mathbf{p}-H\right)
$$

also satisfies :

$$
\max _{\mathbf{b} \in B} \rho\left(\mathbf{b}^{\prime} \mathbf{P}, H\right)
$$

Furthermore, $\rho\left(\mathbf{b}^{\prime} \mathbf{p}, H\right)$ is independent of scale changes of $\mathbf{b}$, so that the additional constraint $\mathbf{b}^{\prime} \mathbf{P b}=1$ has no effect on maximization of $\rho\left(\mathbf{b}^{\prime} \mathbf{p}, H\right)$, and so :

$$
\max _{\substack{\mathbf{b} \in B \\ \mathbf{b}^{\prime} \mathbf{P b}=1}} \rho\left(\mathbf{b}^{\prime} \mathbf{p}, H\right)=\max _{\mathbf{b} \in B} \rho\left(\mathbf{b}^{\prime} \mathbf{p}, H\right)
$$

Therefore the vector $\mathbf{b}$ which satisfies $\min _{\theta} \min _{\mathbf{b} \in B} \operatorname{Var}\left(\mathbf{b}^{\prime} \mathbf{p}-H\right)$ is equivalent to the vector b which satisfies $\max _{\substack{\mathbf{b} \in B \\ \mathbf{b}^{\prime} \mathbf{P}=1}} \rho\left(\mathbf{b}^{\prime} \mathbf{p}, H\right)$, so that the index of HARviLle is equivalent to that of TALLIS, and the difference between them is only a problem of scaling. 
Algebraic verification of their equivalence is also possible. Let us change the scale of the index of TALLIS such that its variance is equal to unity, then, using (2), the index weights become :

$$
\frac{\mathbf{b}_{\mathrm{T}}}{\sigma_{l_{\mathrm{T}}}}=\frac{\theta^{*}}{\sigma_{l_{\mathrm{T}}}} \mathbf{P}^{-1} \mathbf{G}_{1}\left(\mathbf{G}_{1}^{\prime} \mathbf{P}^{-1} \mathbf{G}_{1}\right)^{-1} \mathbf{k}+\frac{1}{\sigma_{l_{\mathrm{T}}}} \mathbf{W G a}
$$

where $\sigma_{\imath_{\mathrm{T}}}$ is the standard deviation of the index of TALLIS, i.e.

$$
\begin{aligned}
\sigma_{l_{\mathrm{T}}} & =\left(\mathbf{b}_{\mathrm{T}}^{\prime} \mathbf{P} \mathbf{b}_{\mathrm{T}}\right)^{1 / 2} \\
& =\left\{\left[\mathbf{a}^{\prime} \mathbf{G}^{\prime} \mathbf{P}^{-1} \mathbf{G}_{1}\left(\mathbf{G}_{1}^{\prime} \mathbf{P}^{-1} \mathbf{G}_{1}\right)^{-1} \mathbf{k}\right]^{2} / \mathbf{k}^{\prime}\left(\mathbf{G}_{1}^{\prime} \mathbf{P}^{-1} \mathbf{G}_{1}\right)^{-1} \mathbf{k}+\mathbf{a}^{\prime} \mathbf{G}^{\prime} \mathbf{W} \mathbf{G a}\right\}^{1 / 2}
\end{aligned}
$$

and :

$$
\mathbf{W}=\left[\mathbf{I}-\mathbf{P}^{-1} \mathbf{G}_{1}\left(\mathbf{G}_{1}^{\prime} \mathbf{P}^{-1} \mathbf{G}_{1}\right)^{-1} \mathbf{G}_{1}^{\prime}\right] \mathbf{P}^{-1}
$$

If we define $\alpha$ as :

$$
\alpha=\theta^{*} / \sigma_{t_{\mathrm{T}}}
$$

then :

$$
\boldsymbol{\alpha}^{2}=\left[\mathbf{k}^{\prime}\left(\mathbf{G}_{1}^{\prime} \mathbf{P}^{-1} \mathbf{G}_{1}\right)^{-1} \mathbf{k}\right]^{-1}\left\{1+\frac{\left[\mathbf{k}^{\prime}\left(\mathbf{G}_{1}^{\prime} \mathbf{P}^{-1} \mathbf{G}_{1}\right)^{-1} \mathbf{k}\right]\left(\mathbf{a}^{\prime} \mathbf{G}^{\prime} \mathbf{W G a}\right)}{\left[\mathbf{a}^{\prime} \mathbf{G}^{\prime} \mathbf{P}^{-1} \mathbf{G}_{1}\left(\mathbf{G}_{1}^{\prime} \mathbf{P}^{-1} \mathbf{G}_{1}\right)^{-1} \mathbf{k}\right]^{2}}\right\}^{-1}
$$

Using this $\alpha^{2}$, it can be shown that :

$$
\sigma_{l_{\mathrm{T}}}=\left[1-\alpha^{2} \mathbf{k}^{\prime}\left(\mathbf{G}_{1}^{\prime} \mathbf{P}^{-1} \mathbf{G}_{1}\right)^{-1} \mathbf{k}\right]^{-1 / 2}\left(\mathbf{a}^{\prime} \mathbf{G}^{\prime} \mathbf{W G a}\right)^{1 / 2}
$$

Substituting (6) and (7) into (5), we get :

$$
\begin{aligned}
& \frac{\mathbf{b}_{\mathrm{T}}}{\sigma_{I_{\mathrm{T}}}}=\alpha \mathbf{P}^{-1} \mathbf{G}_{1}\left(\mathbf{G}_{1}^{\prime} \mathbf{P}^{-1} \mathbf{G}_{1}\right)^{-1} \mathbf{k} \\
& +\left[1-\alpha^{2} \mathbf{k}^{\prime}\left(\mathbf{G}_{1}^{\prime} \mathbf{P}^{-1} \mathbf{G}_{1}\right)^{-1} \mathbf{k}\right]^{1 / 2}\left(\mathbf{a}^{\prime} \mathbf{G}^{\prime} \mathbf{W} \mathbf{G a}\right)^{-1 / 2} \mathbf{W} \mathbf{G a}
\end{aligned}
$$

This formula is exactly the same as the result derived by HaRville (1975). Thus the index of Harville is identical to that of TAllis, and the index weights of Harville can be written as :

$$
\mathbf{b}_{\mathrm{H}}=\mathbf{b}_{\mathrm{T}} / \boldsymbol{\sigma}_{\mathrm{t}_{\mathrm{T}}}
$$

\section{The index of KEMPTHORNE \& NORDSKOG (1959)}

Now we will describe the index of Kempthorne \& Nordskog (1959) aiming at proportional progresses in component traits. This method was stated by KEMPTHORNE \& NoRDSKOG themselves briefly in their numerical example, and a more general discussion was made by Mallard (1972). Mallard suggested that the $r$ proportional constraint equations of (1) can be converted into $(r-1)$ equations representing zero progress constraints of linear combinations of characters. This conversion is made as follows. 
Let us partition $\mathbf{G}_{1}^{\prime}$ and $\mathbf{k}$ as :

$$
\mathbf{G}_{1}^{\prime}=\left[\begin{array}{l}
\mathbf{G}_{0}^{\prime} \\
\mathbf{g}_{r}^{\prime}
\end{array}\right], \mathbf{k}=\left[\begin{array}{l}
\mathbf{k}_{1} \\
k_{r}
\end{array}\right]
$$

where $\mathbf{G}_{0}^{\prime}$ is an $(r-1) \times t$ matrix, $\mathbf{g}_{r}^{\prime}$ is a $1 \times t$ vector, $\mathbf{k}_{0}$ is an $(r-1) \times 1$ vector and $k_{r}$ is the $r$-th element of $\mathbf{k}$. Here we assume that $k_{r}$ is not equal to zero. Then the equations (1) can be rewritten as :

$$
\left[\begin{array}{l}
\mathbf{G}_{0}^{\prime} \\
\mathbf{g}_{r}^{\prime}
\end{array}\right] \mathbf{b}=\boldsymbol{\theta}\left[\begin{array}{l}
\mathbf{k}_{\mathrm{r}} \\
k_{r}
\end{array}\right]
$$

From the last equation, we get :

$$
\theta=\frac{\mathbf{g}_{r}^{\prime} \mathbf{b}}{k_{r}}
$$

Substituting this into the first $(r-1)$ equations of $(8)$, we get :

$$
\begin{aligned}
& \mathbf{G}_{0}^{\prime} \mathbf{b}-\mathbf{k}_{t} \frac{\mathbf{g}_{r}^{\prime} \mathbf{b}}{k_{r}}=\mathbf{0} \\
& {\left[k_{r} \mathbf{I} \mid \mathbf{0}\right]\left[\begin{array}{c}
\mathbf{G}_{0}^{\prime} \\
\mathbf{g}_{r}^{\prime}
\end{array}\right] \mathbf{b}-\left[0 \mid \mathbf{k}_{0}\right]\left[\begin{array}{c}
\mathbf{G}_{0}^{\prime} \\
\mathbf{g}_{r}^{\prime}
\end{array}\right] \mathbf{b}=\mathbf{0}}
\end{aligned}
$$

and finally :

$$
\mathbf{C}^{\prime} \mathbf{G}_{1}^{\prime} \mathbf{b}=\mathbf{0}
$$

where $\mathbf{C}^{\prime}$ is $(r-1) \times r$ matrix which is expressed as :

$$
\mathbf{C}^{\prime}=\left[\begin{array}{lllcc}
k_{r} & 0 & \ldots & 0 & -k_{1} \\
0 & k_{r} \ldots & 0 & -k_{2} \\
\vdots & \vdots & & \vdots & \vdots \\
0 & 0 & \ldots & k_{r} & -k_{r-1}
\end{array}\right]
$$

and $k_{i}(i=1 \ldots r)$ is the $i$-th element of $\mathbf{k}$.

The selection index of KEMPTHORNE \& NordSKog can be derived by minimizing $\operatorname{Var}(I-H)$ subject to the constraints (9), then we get :

$$
\left[\begin{array}{cc}
\mathbf{P} & \mathbf{G}_{1} \mathbf{C} \\
\mathbf{C}^{\prime} \mathbf{G}_{1}^{\prime} & \mathbf{0}
\end{array}\right]\left[\begin{array}{l}
\mathbf{b} \\
\boldsymbol{\lambda}
\end{array}\right]=\left[\begin{array}{c}
\mathbf{G a} \\
\mathbf{0}
\end{array}\right]
$$


where $\boldsymbol{\lambda}$ is a vector of Lagrange multipliers. Solving these equations as to $\mathbf{b}$, we get :

$$
\mathbf{b}_{\mathrm{K}}=\left[\mathbf{I}-\mathbf{P}^{-1} \mathbf{G}_{1} \mathbf{C}\left(\mathbf{C}^{\prime} \mathbf{G}_{1}^{\prime} \mathbf{P}^{-1} \mathbf{G}_{1} \mathbf{C}\right)^{-1} \mathbf{C}^{\prime} \mathbf{G}_{1}^{\prime}\right] \mathbf{P}^{-1} \mathbf{G a}
$$

However, Mallard's definition of $\mathbf{C}^{\prime}$ expressed in (10) is not complete. He merely gave one example of $\mathbf{C}^{\prime}$. Now we must make it clear what conditions the matrix $\mathbf{C}^{\prime}$ should satisfy.

Lemma 1. Let $\mathbf{C}^{\prime}$ be an $(r-1) \times r$ matrix, and put $B=\left\{\mathbf{b} \mid \mathbf{G}_{1}^{\prime} \mathbf{b}=\theta \mathbf{k}, \theta\right.$ arbitrary $\}$ and $B_{0}=\left\{b \mid C^{\prime} \mathbf{G}_{1}^{\prime} \mathbf{b}=\mathbf{0}\right\}$. If $\mathbf{C}^{\prime}$ has rank $(r-1)$ and $\mathbf{C}^{\prime} \mathbf{k}=\mathbf{0}$, then $B=B_{0}$.

Proof. Pre-multiplying $\mathbf{G}_{1}^{\prime} \mathbf{b}=\theta \mathbf{k}$ by $\mathbf{C}^{\prime}$, we get $\mathbf{C}^{\prime} \mathbf{G}_{1}^{\prime} \mathbf{b}=\theta \mathbf{C}^{\prime} \mathbf{k}=\mathbf{0}$,- so that $\mathbf{b} \in B \quad \Longrightarrow \quad \mathbf{b} \in \boldsymbol{B}_{0}$. Conversely, if $\mathbf{C}^{\prime}\left(\mathbf{G}_{i}^{\prime} \mathbf{b}\right)=\mathbf{0}, \mathbf{G}_{1}^{\prime} \mathbf{b}$ belongs to the null-space of $\mathbf{C}^{\prime}$ and has dimension one, but $\mathbf{k}$ also belongs to that space $\left(\mathbf{C}^{\prime} \mathbf{k}=\mathbf{0}\right)$, so that $\mathbf{G}_{1}^{\prime} \mathbf{b}=\theta \mathbf{k}$ for some $\theta$. Therefore $\mathbf{b} \in B_{0} \Rightarrow b \in B$.

From this lemma, the matrices

$$
\mathbf{C}^{\prime}=\left[\begin{array}{cccccc}
k_{2} & -k_{1} & 0 & \ldots & 0 & 0 \\
0 & k_{3} & -k_{2} \ldots & 0 & 0 \\
\vdots & \vdots & \vdots & \vdots & \vdots \\
0 & 0 & 0 & \ldots & k_{\mathrm{r}} & -k_{r-1}
\end{array}\right],\left[\begin{array}{ccccc}
k_{2} & -k_{1} & 0 & \ldots & 0 \\
k_{3} & 0 & -k_{1} \ldots & 0 \\
\vdots & \vdots & \vdots & \vdots \\
k_{r} & 0 & 0 & \ldots & -k_{1}
\end{array}\right]
$$

are also accepted in (9), because these satisfies the conditions that $\mathbf{C}^{\prime} \mathbf{k}=\mathbf{0}$ and $\mathbf{C}^{\prime}$ has rank $(r-1)$. From this fact, it is clear that $\mathbf{C}^{\prime}$ is not unique and various $\mathbf{C}^{\prime}$ s exist.

Let $\mathbf{A}^{\prime}$ be an arbitrary $r \times r$ non-singular matrix and put $\mathbf{C}_{0}^{\prime}=\mathbf{A}^{\prime} \mathbf{C}^{\prime}$. Then $\mathbf{C}_{0}^{\prime} \mathbf{k}=\mathbf{0}$ and $\mathbf{C}_{0}^{\prime}$ has rank $(r-1)$, so that $\mathbf{C}_{0}^{\prime}$ also satisfies the conditions given in lemma 1 . The index weights using this $\mathbf{C}_{0}^{\prime}$ can be expressed as :

$$
\begin{aligned}
\mathbf{b}_{\mathrm{K}}^{0} & =\left[\mathbf{I}-\mathbf{P}^{-1} \mathbf{G}_{1} \mathbf{C}_{0}\left(\mathbf{C}_{0}^{\prime} \mathbf{G}_{1}^{\prime} \mathbf{P}^{-1} \mathbf{G}_{1} \mathbf{C}_{6}\right)^{-1} \mathbf{C}_{0} \mathbf{G}_{1}^{\prime}\right] \mathbf{P}^{-1} \mathbf{G} \mathbf{a} \\
& =\left[\mathbf{I}-\mathbf{P}^{-1} \mathbf{G}_{1} \mathbf{C A}\left(\mathbf{A}^{\prime} \mathbf{C}^{\prime} \mathbf{G}_{1}^{\prime} \mathbf{P}^{-1} \mathbf{G}_{1} \mathbf{C A}\right)^{-1} \mathbf{A}^{\prime} \mathbf{C}^{\prime} \mathbf{G}_{1}^{\prime}\right] \mathbf{P}^{-1} \mathbf{G} \mathbf{a} \\
& =\left[\mathbf{I}-\mathbf{P}^{-1} \mathbf{G}_{1} \mathbf{C}\left(\mathbf{C}^{\prime} \mathbf{G}_{1} \mathbf{P}^{-1} \mathbf{G}_{1} \mathbf{C}\right)^{-1} \mathbf{C}^{\prime} \mathbf{G}_{1}^{\prime}\right] \mathbf{P}^{-1} \mathbf{G} \mathbf{a} \\
& =\mathbf{b}_{\mathrm{K}}
\end{aligned}
$$

Therefore various $C^{\prime}$ 's exist and all of them give the identical index. One may choose any matrix $\mathbf{C}^{\prime}$, but we think the one defined by (10) is the easiest to construct.

\section{Equivalence of the indices}

The index of Tallis is given by $\mathbf{b}$ which satisfies :

$$
\min _{\theta} \min _{\mathbf{b} \in B} \operatorname{Var}\left(\mathbf{b}^{\prime} \mathbf{p}-H\right)
$$

where $B=\left\{\mathbf{b} \mid \mathbf{G}_{1}^{\prime} \mathbf{b}=\theta \mathbf{k}, \theta\right.$ arbitrary $\}$. On the other hand, the index of KempthorNe \& NoRDSKOG is given by $b$ which satisfies :

$$
\min _{\mathbf{b} \in B_{11}} \operatorname{Var}\left(\mathbf{b}^{\prime} \mathbf{p}-\boldsymbol{H}\right)
$$


where $B_{0}=\left\{\mathbf{b} \mid \mathbf{C}^{\prime} \mathbf{G}_{1}^{\prime} \mathbf{b}=\mathbf{0}\right\}$. The lemma 1 in the previous section shows that $B=B_{0}$ if $\mathbf{C}^{\prime} \mathbf{k}=\mathbf{0}$ and $\mathbf{C}^{\prime}$ has rank $(r-1)$. Thus :

$$
\min _{\theta} \min _{\mathbf{b} \in B} \operatorname{Var}\left(\mathbf{b}^{\prime} \mathbf{p}-H\right)=\min _{\mathbf{b} \in B_{\|}} \operatorname{Var}\left(\mathbf{b}^{\prime} \mathbf{p}-H\right)
$$

which shows that the index of TAllis is equivalent to that of KempTHORNE \& NORDSKOG.

Algebraic verification of their equivalence is also possible. Now we need to use the following lemma.

Lemma 2. (Khatri, 1966). Let $\mathbf{X}_{n \times q}$ and $\mathbf{Y}_{n \times(n-q)}$ be of rank $q$ and $(n-q)$ such that $\mathbf{Y}^{\prime} \mathbf{X}=\mathbf{0}$. Then if $\mathbf{M}_{n \times n}$ is a symmetric positive definite matrix, then :

$$
\mathbf{Y}\left(\mathbf{Y}^{\prime} \mathbf{M Y}\right)^{-1} \mathbf{Y}^{\prime}=\mathbf{M}^{-1}-\mathbf{M}^{-1} \mathbf{X}\left(\mathbf{X}^{\prime} \mathbf{M}^{-1} \mathbf{X}\right)^{-1} \mathbf{X}^{\prime} \mathbf{M}^{-1}
$$

Proof. Because $\mathbf{M}$ is symmetric positive definite, there exists a non-singular matrix $\mathbf{T}_{n \times n}$ such that $\mathbf{M}=\mathbf{T T}^{\prime}$. Similarly let $\left(\mathbf{X}^{\prime} \mathbf{M}^{-1} \mathbf{X}\right)^{-1}=\mathbf{Q} \mathbf{Q}^{\prime}$ and $\left(\mathbf{Y}^{\prime} \mathbf{M Y}\right)^{-1}=\mathbf{R} \mathbf{R}^{\prime}$ where $\mathbf{Q}_{q \times ،}$ and $\mathbf{R}_{(n-q) \times(n-q)}$ are non-singular matrices. Then if $\mathbf{S}_{n \times n}=\left[\mathbf{T}^{-1} \mathbf{X Q} \mid \mathbf{T}^{\prime} \mathbf{Y} \mathbf{R}\right], \mathbf{S}^{\prime} \mathbf{S}=\mathbf{I}_{n}$, and so $\mathbf{I}_{n}=\mathbf{S} \mathbf{S}^{\prime}=\mathbf{T}^{-1} \mathbf{X}\left(\mathbf{Q Q} \mathbf{Q}^{\prime}\right) \mathbf{X}^{\prime} \mathbf{T}^{\prime-1}+\mathbf{T}^{\prime} \mathbf{Y}\left(\mathbf{R} \mathbf{R}^{\prime}\right) \mathbf{Y}^{\prime} \mathbf{T}$. From this, we get the lemma.

$\mathbf{C}^{\prime}$ has order $(r-1) \times r$ and rank $(r-1)$, $\mathbf{k}$ has order $r \times 1$ and $\operatorname{rank} 1, \mathbf{C}^{\prime} \mathbf{k}=\mathbf{0}$ and $\mathbf{G}_{1}^{\prime} \mathbf{P}^{-1} \mathbf{G}_{1}$ is symmetric positive definite. Therefore, using this lemma, it can be shown that :

$$
\begin{aligned}
& \mathbf{C}\left(\mathbf{C}^{\prime} \mathbf{G}_{1}^{\prime} \mathbf{P}^{-1} \mathbf{G}_{1} \mathbf{C}\right)^{-1} \mathbf{C}^{\prime}=\left(\mathbf{G}_{1}^{\prime} \mathbf{P}^{-1} \mathbf{G}_{1}\right)^{-1} \\
& -\left(\mathbf{G}_{1}^{\prime} \mathbf{P}^{-1} \mathbf{G}_{1}\right)^{-1} \mathbf{k}\left[\mathbf{k}^{\prime}\left(\mathbf{G}_{1}^{\prime} \mathbf{P}^{-1} \mathbf{G}_{1}\right)^{-1} \mathbf{k}\right]^{-1} \mathbf{k}^{\prime}\left(\mathbf{G}_{1}^{\prime} \mathbf{P}^{-1} \mathbf{G}_{1}\right)^{-1}
\end{aligned}
$$

Substituting this into (11), the index weights of Kempthorne \& Nordskog can be rewritten as :

$$
\begin{aligned}
\mathbf{b}_{\mathrm{K}}= & \left\{\mathbf{I}-\mathbf{P}^{-1} \mathbf{G}_{1}\left\{\left(\mathbf{G}_{1}^{\prime} \mathbf{P}^{-1} \mathbf{G}_{1}\right)^{-1}\right.\right. \\
& \left.\left.-\left(\mathbf{G}_{1}^{\prime} \mathbf{P}^{-1} \mathbf{G}_{1}\right)^{-1} \mathbf{k}\left[\mathbf{k}^{\prime}\left(\mathbf{G}_{1}^{\prime} \mathbf{P}^{-1} \mathbf{G}_{1}\right)^{-1} \mathbf{k}\right]^{-1} \mathbf{k}^{\prime}\left(\mathbf{G}_{1}^{\prime} \mathbf{P}^{-1} \mathbf{G}_{1}\right)^{-1}\right\} \mathbf{G}_{1}^{\prime}\right\} \mathbf{P}^{-1} \mathbf{G a} \\
= & {\left[\mathbf{I}-\mathbf{P}^{-1} \mathbf{G}_{1}\left(\mathbf{G}_{1}^{\prime} \mathbf{P}^{-1} \mathbf{G}_{1}\right)^{-1} \mathbf{G}_{1}^{\prime}\right] \mathbf{P}^{-1} \mathbf{G a}+\phi \mathbf{P}^{-1} \mathbf{G}_{1}\left(\mathbf{G}_{1}^{\prime} \mathbf{P}^{-1} \mathbf{G}_{1}\right)^{-1} \mathbf{k} }
\end{aligned}
$$

where :

$$
\phi=\mathbf{a}^{\prime} \mathbf{G}^{\prime} \mathbf{P}^{-1} \mathbf{G}_{1}\left(\mathbf{G}_{1}^{\prime} \mathbf{P}^{-1} \mathbf{G}_{1}\right)^{-1} \mathbf{k} / \mathbf{k}^{\prime}\left(\mathbf{G}_{1}^{\prime} \mathbf{P}^{-1} \mathbf{G}_{1}\right)^{-1} \mathbf{k}
$$

The formulae (12) and (13) are exactly the same as (2) and (4).

Now the index of Kempthorne \& Nordskog has been proved to be equivalent to that of Tallis. In section IV, the index of HARville was proved to be equivalent to that of TALLIS, so that all 3 indices have been proved to be equivalent.

\section{Discussion}

It is difficult to determine which index is the most desirable among three, because all of them are equivalent. The index of HarviLle, however; seems much more complicated than the others. 
These indices are not always appropriate and there are cases when application of them leads to shifting the population means in the opposite direction to the predetermined desired direction, as described in section III. Such cases are caused by contradiction between the predetermined desired direction of improvement and the desired direction for improvement of total economic merit of the population, i.e. contradiction between the vectors a and $\mathbf{k}$. We must always examine the existence of the contradiction when we construct the index. If we use the index of TALLIS, we can examine it by the sign of $\theta^{*}$ of (4), which is given in the process of calculation of the index. Of course, it is also possible to examine it by the signs of the elements of $E\left(\Delta \mathbf{g}_{1}\right)$, even if we use the index of Kempthorne \& Nordskog.

If $\theta^{*} \leqq 0$, then any index with such $\mathbf{a}$ and $\mathbf{k}$ has no meaning in practice, and we must re-determine the vectors $\mathbf{a}$ and $\mathbf{k}$ appropriately such that $\theta^{*}>0$ if possible. If it is impossible, then it is desirable to adopt the index weights given by :

$$
\mathbf{b}=\mathbf{P}^{-1} \mathbf{G}_{1}\left(\mathbf{G}_{1}^{\prime} \mathbf{P}^{-1} \mathbf{G}_{1}\right)^{-1} \mathbf{k}
$$

which leads to the greatest improvement in predetermined desired direction independently of economic weights as described in section III. Brascamp (1979) \& ITOH \& YamaDA (1986) discussed further about this problem. This index was also discussed by TALLIS (1985) as the optimal index in the special case that $\mathbf{a}_{2}=\mathbf{0}$. In a more special case when the number of traits taken into the index and the number of traits on which proportional constraints are imposed are the same, i.e. $t=r$, the index weights reduce to :

$$
\mathbf{b}=\left(\mathbf{G}^{\prime}\right)^{-1} \mathbf{k}
$$

irrespective of economic weights, which was discussed by PESEK \& BAKER (1969) and also by YAMADA et al. (1975).

\section{Numerical example}

Suppose a breeder wants to improve his flock of poultry using a selection index. Traits involved in the index and genetic parameters of his flock are given in table 1. Relative economic weights and proportional desired gains are also given in the table. It is assumed that he is not interested in a proportional gain in feed requirement.

Using the notations stated above, the parameters required to construct the index are given as follows.

$$
\begin{aligned}
& t=4, \quad r=3 \\
& \mathbf{G}=\left[\begin{array}{rrrr}
8.0000 & 0.1288 & -7.5895 & -10.1193 \\
& 0.0130 & 0 . & 0.3055 \\
& & 20.0000 & -24.0000 \\
& & & 80.0000
\end{array}\right]
\end{aligned}
$$




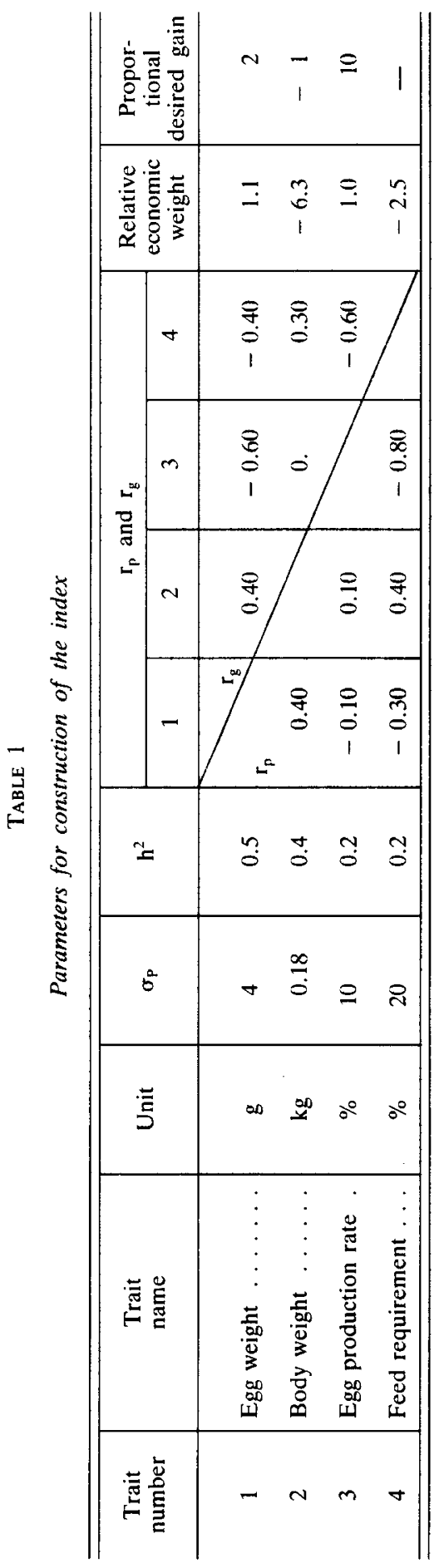




$$
\begin{aligned}
& \mathbf{G}_{1}=\left[\begin{array}{rlc}
8.0000 & 0.1288 & -7.5895 \\
0.1288 & 0.0130 & 0 . \\
-7.5895 & 0 . & 20.0000 \\
-10.1193 & 0.3055 & -24.0000
\end{array}\right] \quad, \mathbf{G}_{2}=\left[\begin{array}{r}
-10.1193 \\
0.3055 \\
-24.0000 \\
80.0000
\end{array}\right] \\
& \mathbf{P}=\left[\begin{array}{rrrr}
16.0000 & 0.2880 & -4.0000 & -24.0000 \\
& 0.0324 & 0.1800 & 1.4400 \\
& & 100.0000 & -160.0000 \\
& & & 400.0000
\end{array}\right] \text {, } \\
& \mathbf{a}=\left[\begin{array}{llll}
1.1 & -6.3 & 1.0 & -0.25
\end{array}\right]^{\prime} \\
& \mathbf{a}_{1}=\left[\begin{array}{lll}
1.1 & -6.3 & 1.0
\end{array}\right]^{\prime}, \mathbf{a}_{2}=\left[\begin{array}{l}
-0.25
\end{array}\right] \\
& \mathbf{k}=\left[\begin{array}{lll}
2 & -1 & 10
\end{array}\right]^{\prime}
\end{aligned}
$$

First, we will illustrate the index of Tallis.

$$
\begin{aligned}
& {\left[\mathbf{I}-\mathbf{P}^{-1} \mathbf{G}_{1}\left(\mathbf{G}_{1}^{\prime} \mathbf{P}^{-1} \mathbf{G}_{1}\right)^{-1} \mathbf{G}_{1}^{\prime}\right] \mathbf{P}^{-1} \mathbf{G}_{2} \mathbf{a}_{2}} \\
& =\left[\begin{array}{llll}
0.688556 & -9.642309 & 0.403810 & 0.118768
\end{array}\right]^{\prime} \\
& \mathbf{P}^{-1} \mathbf{G}_{1}\left(\mathbf{G}_{1}^{\prime} \mathbf{P}^{-1} \mathbf{G}_{1}\right)^{-1} \mathbf{k} \\
& =\left[\begin{array}{llll}
-5.413466 & 15.304861 & -3.522812 & -1.640455
\end{array}\right]^{\prime} \\
& \theta^{*}=0.067622
\end{aligned}
$$

Therefore :

$$
\mathbf{b}_{\mathrm{T}}=\left[\begin{array}{llll}
0.322486 & -8.607360 & 0.165589 & 0.007836
\end{array}\right]^{\prime}
$$

Then the standard deviation of the index is :

$$
\sigma_{/ \mathrm{T}}=1.887055
$$

and the expected genetic gains in one generation are :

$$
\begin{aligned}
\mathrm{E}(\Delta \mathbf{g}) & =i \mathbf{G}^{\prime} \mathbf{b}_{\mathrm{T}} / \sigma_{I_{\mathrm{T}}} \\
& =i\left[\begin{array}{llll}
0.071670 & -0.035835 & 0.358348 & -4.89442
\end{array}\right]^{\prime}
\end{aligned}
$$

We can get the index weights of Harville from (14) and (15) as :

$$
\mathbf{b}_{\mathrm{H}}=\mathbf{b}_{\mathrm{T}} / \sigma_{/_{\mathrm{T}}}=\left[\begin{array}{llll}
0.170894 & -4.561267 & 0.087750 & 0.004153
\end{array}\right]^{\prime}
$$

Then the variance of HaRville's index is 1 .

Next, we will illustrate the index of Kempthorne \& Nordskog. Using (10), matrix $\mathbf{C}^{\prime}$ is written as :

$$
\mathbf{C}^{\prime}=\left[\begin{array}{lrr}
10 & 0 & -2 \\
0 & 10 & 1
\end{array}\right]
$$


Using this $\mathbf{C}^{\prime}$, the index weights of Kempthorne \& Nordskog become :

$$
\mathbf{b}_{\mathrm{K}}=\left[\begin{array}{llll}
0.322486 & -0.670360 & 0.165589 & 0.007836
\end{array}\right]^{\prime}
$$

which is exactly the same as (14). We can get the identical result, even if we use the following matrices as $\mathbf{C}^{\prime}$,

$$
\left[\begin{array}{rrr}
-1 & -2 & 0 \\
0 & 10 & 1
\end{array}\right],\left[\begin{array}{rrr}
-1 & -2 & 0 \\
10 & 0 & -2
\end{array}\right] \text {, }
$$

because all of them satisfy the conditions that $\mathbf{C}^{\prime} \mathbf{k}=\mathbf{0}$ and $\mathbf{C}^{\prime}$ has rank $(r-1)=2$.

If the breeder uses another constraint of proportional desired gains, e.g.

$$
\mathbf{k}=\left[\begin{array}{lll}
2 & -0.1 & 10
\end{array}\right]^{\prime}
$$

then the index weights of TaLLIS become :

$$
\mathbf{b}_{1}=\left[\begin{array}{llll}
0.932151 & -13.025209 & 0.539487 & 0.177116
\end{array}\right]^{\prime}
$$

However, $\theta^{*}=-0.053558$ and the signs of the elements of :

$$
\mathrm{E}\left(\Delta \mathbf{g}_{1}\right)=i\left[\begin{array}{llll}
-0.069722 & 0.003486 & -0.348608 & -7.934400
\end{array}\right]^{\prime}
$$

are reverse to those of $\mathbf{k}$, so that this index leads to shifting the flock means in the opposite direction to the predetermined desired direction and so the breeder can not use this index.

Received March 19, 1986.

Accepted August 26, 1986.

\section{Acknowledgement}

We wish to thank the referees for their useful suggestions. This study was supported in part by Grants-in-aid for Scientific Research No. 61304029 from the Ministry of Education, Science and Culture.

\section{References}

Brascamp E.W., 1979. Selection index for desired gains. 30th Annual Meeting of the European Association of Animal Production, July 22-26, 1979, Harrogate, G6.5. (Photocopy).

EssL A., 1981. Index selection with proportional restriction: Another view point. Z. Tierz. Züchtungsbiol., 98, 125-131.

Harville D.A., 1975. Index selection with proportionality constraints. Biometrics, 31, 223-225.

Iтон Y., Yamada Y., 1986. Re-examination of selection index for desired gains. Génét. Sél. Evol., 18, 499-504. 
Khatri C.G., 1966. A note on a MANOVA model applied to problems in growth curve. Ann. Inst. Stat. Math., 18, 75-86.

Kempthorne O., Nordskog A.W., 1959. Restricted selection indices. Biometrics, 15, 10-19.

Mallard J., 1972. La théorie et le calcul des index de sélection avec restrictions: synthèse critique. Biometrics, 28, 713-735.

Pesek J., Baker R.J., 1969. Desired improvement in relation to selection indices. Can. J. Plant. Sci., 49, 803-804.

Rouvier R., 1977. Mise au point sur le modèle classique d'estimation de la valeur génétique. Ann. Génét. Sél. Anim., 9, 17-26.

TAluis G.M., 1962. A selection index for optimum genotype. Biometrics, 18, 120-122.

TALlis G.M., 1985. Constrained selection. Jpn. J. Genet., 60, 151-155. Corrigendum and addendum, Jpn. J. Genet., 61, 181-184.

Yamada Y., Yokouchi K., Nishida A., 1975. Selection index when genetic gains of individual traits are of primary concern. Jpn. J. Genet., 50, 33-41. 